\section{Organizing the flow of physiotherapy services: agreement between clinical perception and a referral protocol}

\author{
Organização do fluxo de serviços \\ fisioterapêuticos: concordância \\ entre percepção clínica e protoco
}

Lorrane Brunelle Moreira (1) ${ }^{1}$

Fernanda Lurdes Souza Cruz (1) 1

Túlio Lima da Silva (1) ${ }^{2}$

Silvia Lanziotti de Azevedo Silva (10 ${ }^{3 *}$

\footnotetext{
1 Universidade Federal de Alfenas (UNIFAL), Alfenas, MG, Brazil ${ }^{2}$ Prefeitura Municipal de Alfenas, MG, Brazil

${ }^{3}$ Universidade Federal de Juiz de Fora (UFJF), Juiz de Fora, MG, Brazil
}

Date of first submission: February 1, 2020

Last received: October 20, 2020

Accepted: March 1, 2021

Associate editor: Angelica Vieira Cavalcanti de Sousa

*Correspondence: silviafisiojf@yahoo.com.br

\begin{abstract}
Introduction: Protocols to organize the flow of treatment between primary and secondary healthcare levels help physiotherapists working in Primary Health Care (PHC) determine which cases will remain at the primary level and which should be referred to the secondary level for specialized treatment. Objective: Assess the agreement between the clinical perception of physiotherapists and the protocol in organizing the flow of physiotherapy patients.

Methods: This is a methodological cross-sectional study based on the analysis of secondary data, recorded on a service spreadsheet, with respect to the clinical perception of 4 physiotherapists working in $\mathrm{PHC}$ and the protocol they apply to determine the urgency for referral to the secondary care level, considering physiotherapy specialties. Assessment was expressed as the percentage agreement, magnitude and significance according to the Kappa test, with $>0.80$ considered perfect agreement. Analyses were conducted using SPSS 21.0 statistical software at a significance level of $\alpha=0.05$. Results: In 619 of 715 referrals, the perception of physiotherapists corroborated with the protocol in terms of patient referral to the secondary service. The percentage agreement for urgency classification in the total sample was $71 \%$ and the Weighted Kappa index 0.3710 (CI95\% 0.3029-0.4391). The instrument exhibited high agreement in the areas of musculoskeletal physiotherapy (94.7\%) and gerontology (98.2\%), and low in urogynecology (27.6\%). Conclusion: The protocol showed a high percentage of agreement and may be an important instrument in organizing the flow of physiotherapy services and could be enhanced for use in other specialties.
\end{abstract}

Keywords: Physiotherapy. Health regulation and inspection. Primary health care. Secondary health care. 


\section{Resumo}

Introdução: Protocolos para organização do fluxo dos atendimentos entre os níveis primário e secundário de atenção ajudam o fisioterapeuta atuante na Atenção Primária à Saúde (APS) a determinar quais casos serão mantidos no primeiro nível e quais devem ser encaminhados para o nível secundário, onde receberão atendimento especializado. Objetivo: Avaliar a concor-dância entre percepção clínica dos fisioterapeutas e protocolo na organização do fluxo de usuários de serviço de fisioterapia. Métodos: Estudo transversal metodológico baseado em análise de dados secundários, registrados em planilha do serviço, referentes à percepção clínica de quatro fisioterapeutas atuantes na APS e protocolo aplicado por eles para determinação do encaminhamento e caráter de urgência para o nível secundário da rede de atenção, considerando as especialidades da fisioterapia. A avaliação expressou-se pelo percentual de concordância, magnitude e significância pelo teste Kappa, considerando > 0,80 concordância perfeita. As análises foram realizadas no pacote estatístico SPPS 21.0, nível de significância $\alpha=0,05$. Resultados: Considerando 715 encaminhamentos, em 619 a percepção dos fisioterapeutas corroborou com a determinação do protocolo em relação ao encaminhamento do usuário para o serviço secundário. O percentual de concordância relativo à classificação urgência, na amostra total, foi de $71 \%$ e o índice de Kappa Ponderado foi 0,3710 (IC95\% 0,3029-0,4391). O instrumento apresentou maior concordância nas áreas de muscoloesquelética $(94,7 \%)$ e gerontologia (98,2\%), e menor concordância na uroginecologia

(27,6\%). Conclusão: O protocolo apresentou importante percentual de concordância, podendo ser instrumento importante na organização de fluxos de serviços de fisioterapia e ser aprimorado para o uso em várias especialidades.

Palavras-chave: Fisioterapia. Regulação e fiscalização em saúde. Atenção primária à saúde. Atenção secundária à saúde.

\section{Introduction}

The Ministry of Health described Health Care Networks (HCN) as a strategy to restructure the Brazilian National Health System (SUS), which aims to provide effective and efficient services. ${ }^{1} \mathrm{HCN}$ s are polyarchy organizations of health services, consisting of primary, secondary and tertiary healthcare levels. Their objective is to provide continuous comprehensive care to the population and are coordinated by Primary Health Care $(\mathrm{PHC})$, which is the patients' initial contact and entry point to the health system. ${ }^{1,2}$ Physiotherapy services were long excluded from $\mathrm{PHC}$, possibly due to the initial nature of the profession, whose focus was primarily curative and rehabilitative. Before its inclusion PHC, patients only had access to physiotherapy when referred to specialized secondary care and tertiary hospitals, which hindered the access of the general population. ${ }^{3}$

Physiotherapy practices can be developed in different healthcare specialties and its field of action is quite broad, encompassing musculoskeletal, adult and child neurofunctional, cardiac rehabilitation, dermatofunctional, gerontological, pulmonary rehabilitation, and urogynecological specialties, among others. Physiotherapists have ample knowledge to act in all levels of care, given that $\mathrm{PHC}$ is a more generalist field. ${ }^{4}$

Knowledge inherent to physiotherapy may contribute to preventing disease and sequelae in addition to promoting health and preventing disorders. Including physiotherapy in $\mathrm{PHC}$ reduces the need for referrals to other HCN levels due to the demand for physiotherapy services, thereby lowering public expenditures and contributing to changing the healthcare model. 5,6 Physiotherapists in PHC must use their resolution capacity to individually or collectively determine which cases are a priority and should be referred to the secondary level. To that end, they must be armed with the knowledge and tools needed during the assessment process. ${ }^{7}$ In this respect, referral protocols have been developed, which are both management and healthcare tools, since they not only guide the decisions of the professionals, but are also a reference during assessment. 8,9

Silva et al. ${ }^{10}$ created and implemented a referral protocol in the physiotherapy service of Basic Health Units (BHUs). The protocol was developed based on International Classification of Functioning, Disability and Health (ICF) domains: health condition, body structure and function, activities, social participation, personal factors and environmental factors. The maximum score on the protocol is 26 points, 9 points being the minimum for referral, followed by urgency criteria, as follows: non-urgent (9-15 points), urgent (16-21 points), and very urgent (22-26 points). ${ }^{10}$ The use of this protocol proved to be important as a filter for referrals that could possibly be resolved in PHC, organizing the flow to the secondary level and reducing 
waiting times. The physiotherapy services do not have another similar protocol and, as such, the ICF was used as the basis for its creation. ${ }^{10}$

However, no study has been conducted to determine the agreement between the results of this protocol and the clinical perception of physiotherapists in $\mathrm{PHC}$. Without complementary instruments, physiotherapists use their perception to define patient referrals. In addition, the principle of equity assumes that the flow of patients is in line with urgency criteria, and it is important to verify the magnitude of agreement between the classification of patients referred to secondary care, which determines their waiting time. Thus, the aim of the present study was to assess the agreement between the clinical perception of PHC physiotherapists and the referral protocol proposed by Silva et. al., ${ }^{10}$ to determine referrals and the degree of urgency of patients treated at a municipal public physiotherapy facility.

\section{Methods}

This is a methodological cross-sectional study to assess the agreement between a referral protocol ${ }^{10}$ and the clinical perception of professionals, considered their personal judgment regarding the need to refer the patient. The study was conducted in Alfenas, municipality of Southern Minas Gerais state, between November 2018 and July 2019. It was approved by the Municipal Health Department of Alfenas and by the Research Ethics Committee of the Federal University of Alfenas (Protocol no. 3.155.997).

The public physiotherapy service of the municipality employs four physiotherapists in $\mathrm{PHC}$ to give support to 20 BHUs, five for each professional. They treat individuals, groups, or patients at home, in addition to applying the protocol to organize the flow and determine those who will remain in $\mathrm{PHC}$ or be referred to the secondary level. Before the protocol was implemented, there was no standardization and most cases were referred, creating long waiting lists, overloading the second level and hindering patient access. ${ }^{10}$ The second level consists of the teaching clinic of a public university, whose treatment is divided into the following specialties: musculoskeletal, adult and child neurofunctional, cardiac and pulmonary rehabilitation, dermato-functional, urogynecological, aquatic physiotherapy and gerontology.
At the time the protocol was implemented in the public physiotherapy system, a survey of the number of referrals on a waiting list for PHC treatment resulted in a total of 1524 individuals, potential targets for application. The protocol has become part of the work routine of physiotherapists and after its application, the patient is given one of the following directives: remain in PHC for individual or group treatment, or referred to the secondary level, according to the nature of the urgency. ${ }^{10}$ The four physiotherapists were trained to apply the protocol and include it in their work routine by order of municipal authorities. The patients whose referrals had accumulated were screened by the protocol (Figure 1).

After the protocol is applied, the physiotherapist is allowed to refer patients to the secondary service and define urgency based on the protocol score, but also on their practical experience and knowledge, that is, their clinical perception. Physiotherapists record their perception and protocol score of the referred patients on a spreadsheet, in separate columns. The standardized spreadsheet is an online tool, accessed by a professional to schedule patients when vacancies become available in the teaching clinic, according to the nature of the urgency. The patients treated by physiotherapists in $\mathrm{PHC}$ are assessed only by the professional on duty at the $\mathrm{BHU}$ in question, who is the only individual authorized to apply the protocol and insert the data on the spreadsheet when necessary.

\section{Survey of study data}

The data used in the present study were obtained from the spreadsheet filled out by the physiotherapist to organize the patients referred to the specialized service. The professional responsible for the information on the municipal spreadsheet gave written permission for the researchers to access the data. The information recorded included age, classification by degree of urgency and protocol score, degree of urgency according to the physiotherapist's perception, and specialty of the physiotherapist the patient was referred to.

All the referrals included in the spreadsheet after analysis of the agreement between the protocol and the physiotherapist's clinical perception in relation to referrals to the secondary level were considered. To assess the agreement of urgency classification, only those referred by both the protocol and the physiotherapists' perception were considered. 


\begin{tabular}{|c|c|c|}
\hline \multicolumn{3}{|l|}{ Patient identification: } \\
\hline \multicolumn{3}{|c|}{ 1) Data regarding the disease/pathology (maximum 7 points) } \\
\hline \multicolumn{3}{|l|}{ Clinical diagnosis: } \\
\hline \multirow{2}{*}{ Time since onset current/main symptoms } & \multirow{2}{*}{$\begin{array}{l}\text { (3) Less than } 3 \text { months } \\
\text { (2) } 3 \text { - } 6 \text { months } \\
\text { (1) } 6 \text { months - } 1 \text { year } \\
\text { (0) More than } 1 \text { year }\end{array}$} & \\
\hline & & \\
\hline \multirow[t]{2}{*}{ Progressive condition } & (1) Yes & Score: \\
\hline & (0) No & \\
\hline \multirow[t]{2}{*}{ Severe postural disturbance } & (1) Yes & Score: \\
\hline & (0) No & \\
\hline Surgery & (0) No & \\
\hline \multicolumn{3}{|l|}{ 2) Pain (maximum 7 points) } \\
\hline \multirow[t]{2}{*}{ Feeling pain } & (1) Yes & Score: \\
\hline & (0) No & \\
\hline \multirow[t]{3}{*}{ Pain intensity (Visual Analogic Scale) } & (3) 8 - 10 points - veery severe & Score: \\
\hline & (2) 5 - 7 points - moderate & \\
\hline & (1) 1 - 4 points - mild & \\
\hline \multirow[t]{2}{*}{ Time experiencing current pain } & (3) Less than 3 months & Score: \\
\hline & (2) 3 - 6 months & \\
\hline \multirow{3}{*}{$\begin{array}{l}\text { If yes, how the patient performs activities of } \\
\text { daily living ( } A D L)\end{array}$} & (3) Does not perform & Score: \\
\hline & (2) With assistance from someone else & \\
\hline & (1) With an assistive device & \\
\hline \multirow[t]{4}{*}{ The patient is currently working } & $\begin{array}{l}\text { (2) Working, but experiencing difficulties due to the current health } \\
\text { condition }\end{array}$ & Score: \\
\hline & (2) Unable to work & \\
\hline & (2) Receiving INSS (Brazilian Social Security Institute) benefits & \\
\hline & (0) Not experiencing difficulties with work/does not work & \\
\hline \multirow[t]{2}{*}{ Social isolation } & (2) Yes & Score: \\
\hline & (0) No & \\
\hline \multicolumn{3}{|l|}{ 4) Cognition (maximum 2 points) } \\
\hline \multirow{2}{*}{$\begin{array}{l}\text { The patient has difficulty understanding } \\
\text { things/expressing himself or herself }\end{array}$} & (1) Yes & Score: \\
\hline & (0) No & \\
\hline \multirow[t]{2}{*}{ The patient is able to follow instructions } & (1) No & Score: \\
\hline & (0) Yes & \\
\hline 5) Caregiver (maximum 2 points) & & \\
\hline In need of a caregiver & (1) Yes & Score: \\
\hline
\end{tabular}

Figure 1 - Referral protocol. ${ }^{10}$ 


\section{Statistical analysis}

The description of the patients included on the spreadsheets was made in percentage values for the categorical variables sex and referral specialty, and mean and standard deviation for the continuous variable age.

The percentage of referrals according to the clinical perception of physiotherapists and protocol score was assessed. The percent agreement of referrals to secondary care was calculated for the total score and for each specialty.

Among the patients for whom there was agreement between the protocol and clinical perception in terms of referrals, agreement was then assessed according to the urgency criterion between the score suggested by the instrument and the clinical perception of the physiotherapists. The magnitude and significance of this agreement was evaluated using Cohen's Kappa coefficient, with values of 0 representing "no agreement", between 0-0.19 "poor", 0.2-0.39 "slight", 0.40-0.59 "moderate", 0.60-0.79 "substantial" 0.80-1.0 "perfect". 11

In cases with no variability between the possible protocol answers and/or professional perception, the Kappa statistic could not be calculated. ${ }^{11}$ The significance of the Kappa coefficient was assessed by the 95\% confidence interval.

Analyses were conducted using the SPSS statistical package, version 21.0 at a significance level of $\alpha=0.05$.

\section{Results}

A total of 715 individuals referred to the secondary physiotherapy service were registered on the standardized spreadsheet. In order to assess agreement regarding urgency criteria, 96 patients were excluded because, according to the protocol, they should remain in $\mathrm{PHC}$, leaving 619 individuals.

All the data on the referred patients were extracted from the spreadsheet. The most common referrals were for musculoskeletal disorders (44.9\%) and the least for cardiac rehabilitation (0.90\%).

The percentage agreement between referrals based on the protocol and the clinical perception of the physiotherapists is presented in Table 2, for the total sample and each specialty. Table 3 shows the percentage agreement and Cohen's Kappa for the nature of the urgency for referrals.

Table 1 - Sociodemographic and descriptive characteristics of the sample

\begin{tabular}{lc}
\hline Variables & $\begin{array}{c}\text { Total sample } \\
(\mathbf{n}=\mathbf{7 1 5})\end{array}$ \\
\hline Age in years (mean \pm standard-deviation) & $53.81 \pm 19.89$ \\
Sex & $\%(\mathbf{n})$ \\
Male & $31(222)$ \\
Female & $69(493)$ \\
Physiotherapy specialties & $\%(\mathbf{n})$ \\
Musculoskeletal & $44.90(321)$ \\
Aquatic physiotherapy & $18.70(134)$ \\
Gerontology & $15.80(113)$ \\
Adult neurofunctional & $8.80(63)$ \\
Urogynecology & $4.10(29)$ \\
Pulmonary rehabilitation & $2.90(21)$ \\
Child neurofunctional & $2.10(15)$ \\
Dermato-functional & $1.80(13)$ \\
Cardiac rehabilitation & $0.90(6)$ \\
\hline
\end{tabular}


Table 2 - Percentage agreement between referrals based on the protocol and the clinical perception of physiotherapist $(\mathrm{n}=715)$

\begin{tabular}{|c|c|c|c|c|c|}
\hline \multirow{2}{*}{ Specialties } & \multicolumn{5}{|c|}{$\begin{array}{l}\text { Classification according to the } \\
\text { Clinical Perception of the } \\
\text { Physiotherapist }\end{array}$} \\
\hline & $\begin{array}{c}\text { Classification } \\
\text { according to } \\
\text { protocol }\end{array}$ & Non-urgent & Urgent & Very urgent & $\begin{array}{l}\text { Percentage of } \\
\text { agreement }(\%)\end{array}$ \\
\hline \multirow{4}{*}{ Total sample } & $\mathrm{PHC}$ & 53 & 38 & 5 & \multirow{4}{*}{86.60} \\
\hline & Non urgent & 363 & 90 & 26 & \\
\hline & Urgent & 36 & 70 & 23 & \\
\hline & Very urgent & 1 & 2 & 8 & \\
\hline \multirow{4}{*}{ Musculoskeletal } & $\mathrm{PHC}$ & 6 & 11 & 0 & \multirow{4}{*}{94.70} \\
\hline & Non urgent & 176 & 47 & 6 & \\
\hline & Urgent & 17 & 37 & 14 & \\
\hline & Very urgent & 0 & 1 & 6 & \\
\hline \multirow[b]{2}{*}{ Child neurofuncitonal } & $\mathrm{PHC}$ & 9 & 1 & 0 & \multirow[b]{2}{*}{33.30} \\
\hline & Non-urgent & 3 & 1 & 1 & \\
\hline \multirow{3}{*}{ Aquatic physiotherapy } & APS & 18 & 2 & 0 & \multirow{3}{*}{85.10} \\
\hline & Não urgente & 78 & 7 & 8 & \\
\hline & Urgente & 7 & 13 & 1 & \\
\hline \multirow{2}{*}{ Cardiac rehabilitation } & $\mathrm{PHC}$ & 0 & 3 & - & \multirow{2}{*}{50.00} \\
\hline & Non-urgent & 1 & 2 & - & \\
\hline \multirow{3}{*}{ Pulmonary rehabilitation } & $\mathrm{PHC}$ & 0 & 9 & 0 & \multirow{3}{*}{57.10} \\
\hline & Non-urgent & 3 & 5 & 1 & \\
\hline & Urgent & 0 & 2 & 1 & \\
\hline \multirow{3}{*}{ Dermato-functional } & PHC & 1 & 0 & 1 & \multirow{3}{*}{84,60} \\
\hline & Non-urgent & 4 & 5 & 0 & \\
\hline & Urgent & 0 & 2 & 0 & \\
\hline \multirow{4}{*}{ Adult neurofunctional } & PHC & 8 & 4 & 0 & \multirow{4}{*}{81.00} \\
\hline & Non-urgent & 19 & 10 & 6 & \\
\hline & Urgent & 2 & 7 & 3 & \\
\hline & Very urgent & 1 & 1 & 2 & \\
\hline \multirow{2}{*}{ Urogynecology } & $\mathrm{PHC}$ & 9 & 8 & 4 & \multirow{2}{*}{27.60} \\
\hline & Non-urgent & 3 & 5 & 0 & \\
\hline \multirow{3}{*}{ Gerontology } & $\mathrm{PHC}$ & 2 & 0 & 0 & \multirow{3}{*}{98.20} \\
\hline & Non-urgent & 76 & 8 & 4 & \\
\hline & Urgent & 10 & 9 & 4 & \\
\hline
\end{tabular}

Note: PHC = Primary Health Care; patients who were not referred to the secondary level, and must remain in PHC for individual or group care. 
Table 3 - Percentage and magnitude of agreement between the nature of the urgency on the protocol and the clinical perception of physiotherapist $(n=619)$

\begin{tabular}{|c|c|c|c|c|c|c|c|}
\hline \multirow[t]{2}{*}{ Specialties } & \multicolumn{5}{|c|}{$\begin{array}{l}\text { Classification according to the } \\
\text { Clinical Perception of the } \\
\text { Physiotherapist }\end{array}$} & \multirow[b]{2}{*}{ Kappa* } & \multirow[b]{2}{*}{$\begin{array}{l}\text { IC95\% } \\
\text { Kappa }\end{array}$} \\
\hline & $\begin{array}{l}\text { Classificação } \\
\text { Pontuação no } \\
\text { Protocolo }\end{array}$ & Non-urgent & Urgent & $\begin{array}{l}\text { Very } \\
\text { urgent }\end{array}$ & $\begin{array}{l}\text { Percentage of } \\
\text { agreement }(\%)\end{array}$ & & \\
\hline \multirow{3}{*}{ Total sample } & Non-urgent & 363 & 90 & 26 & \multirow{3}{*}{71.00} & \multirow{3}{*}{$\begin{array}{l}0.37 \\
\text { Slight }\end{array}$} & \multirow{3}{*}{$0.30-0.43^{\star \star}$} \\
\hline & Urgent & 36 & 70 & 23 & & & \\
\hline & Very urgent & 1 & 2 & 8 & & & \\
\hline \multirow{3}{*}{ Musculoskeletal } & Non-urgent & 176 & 47 & 6 & \multirow{3}{*}{72.00} & \multirow{3}{*}{$\begin{array}{c}0.44 \\
\text { Moderate }\end{array}$} & \multirow{3}{*}{$0.34-0.53^{\star \star}$} \\
\hline & Urgent & 17 & 37 & 14 & & & \\
\hline & Very urgent & 0 & 1 & 6 & & & \\
\hline Child neurofunctional & Non-urgent & 3 & 1 & 1 & 60.00 & NC & NC \\
\hline \multirow{2}{*}{ Aquatic physiotherapy } & Non-urgent & 78 & 7 & 8 & \multirow{2}{*}{79.80} & 0.35 & \multirow{2}{*}{$0.17-0.53$} \\
\hline & Urgent & 7 & 13 & 1 & & & \\
\hline Cardiac rehabilitation & Non-urgent & 1 & 2 & - & 33.30 & NC & NC \\
\hline \multirow{2}{*}{ Pulmonary rehabilitation } & Non-urgent & 3 & 5 & 1 & \multirow{2}{*}{41.60} & \multirow{2}{*}{$\begin{array}{l}0.15 \\
\text { Poor }\end{array}$} & \multirow{2}{*}{$-0.05-0.37$} \\
\hline & Urgent & 0 & 2 & 1 & & & \\
\hline \multirow{2}{*}{ Dermato-functional } & Non-urgent & 4 & 5 & - & \multirow{2}{*}{0.20} & \multirow{2}{*}{$\begin{array}{l}0.35 \\
\text { Slight }\end{array}$} & \multirow{2}{*}{$-0.05-1.02$} \\
\hline & Urgent & 0 & 2 & - & & & \\
\hline \multirow{3}{*}{ Adult neurofunctional } & Non-urgent & 19 & 10 & 6 & \multirow{3}{*}{54.90} & \multirow{3}{*}{$\begin{array}{l}0,25 \\
\text { Slight }\end{array}$} & \multirow{3}{*}{$0.05-0.45^{*}$} \\
\hline & Urgent & 2 & 7 & 3 & & & \\
\hline & Very urgent & 1 & 1 & 2 & & & \\
\hline Urogynecology & Non-urgent & 3 & 5 & - & 37.50 & NC & NC \\
\hline \multirow{2}{*}{ Gerontology } & Non-urgent & 76 & 8 & 4 & \multirow{2}{*}{76.50} & \multirow{2}{*}{$\begin{array}{l}0.34 \\
\text { Slight }\end{array}$} & \multirow{2}{*}{$0.17-0.51^{\star \star}$} \\
\hline & Urgent & 10 & 9 & 4 & & & \\
\hline
\end{tabular}

Note: ${ }^{*} 95 \% \mathrm{Cl}$ significance; ${ }^{*}$ Cohen's Kappa Classification: $0-0.19=$ Poor; $0.2-0.39=$ Slight; $0.4-0.59=$ Moderate; NC = Cohen's Kappa not calculated due to lack of variance between protocol classifications. ${ }^{11}$

\section{Discussion}

The aim of the present study was to assess the agreement between the protocol score and the clinical perception of physiotherapists working in PHC, in terms of the referral and classification of the type of urgency, which determine the flow between primary and secondary care levels. Physiotherapy assessment in PHC is essential in identifying real patient needs, and the use of suitable protocols facilitates this assessment.

Ferrer et al. ${ }^{12}$ found that the lack of humanized care and screening and failure to establish treatment priority cause significant dissatisfaction among patients on long waiting lists. Azevedo and Barbosa ${ }^{13}$ defined screening as the first treatment provided by professionals to users of public health services, aimed at the initial assessment, selection and referral of patients to specialized care. This study demonstrates how protocol-based screening may reflect the clinical perception of physiotherapists and help in decision making, given the $86.6 \%$ agreement between them.

During screening, professionals can determine the true patient need and make the correct decision, but most cases are based on professional experience. ${ }^{13}$ In Ireland, O'Mahony e Blake ${ }^{14}$ analyzed the opinion of physiotherapists about protocols implemented to 
construct a waiting list in orthopedics and rheumatology in the public health sector, finding that $79 \%$ were satisfied with the proposal. Silva et al. ${ }^{10}$ concluded that patient assessment by physiotherapists in PHC is essential to resolve some cases and refer patients truly in need to the secondary care level. Once again, the $86.6 \%$ agreement in relation to referral or remaining in $\mathrm{PHC}$ reinforces the ability of the protocol to help in this matter.

With respect to specialties, the protocol obtained better agreement in terms of referral and urgency classification of musculoskeletal and gerontological disorders, with moderate (0.44) and slight (0.34) Cohen's Kappa, respectively, indicating better protocol performance for screening in these areas. Gerontology aims at a multifactorial approach for older people. A complete gerontological assessment makes it possible to diagnose the functional status of an older individual, the early detection of health problems and proper orientation regarding the actions and services needed. ${ }^{15,16}$ Thus, the protocol should obtain scores that are more suitable for the area of gerontology, since both prioritize functionality in their assessment, especially in terms of the ICF. This result is reinforced by the $98.2 \%$ agreement in relation to referral to secondary care and $76.5 \%$ for urgency classification of older patients referred to the secondary service of the municipality.

Disorders that affect the musculoskeletal system are the second most treated by doctors and hospitals in Brazil, in addition to causing functional changes, compromising the individual's activities of daily living and social interaction, domains that are considered during protocol screening. ${ }^{17}$ Kennedy et al. ${ }^{18}$ and Matifat et al. ${ }^{19}$ observed that most of the demand for physiotherapy services was for problems linked to bones, muscles and joints, demonstrating the importance of prioritizing acute cases, thereby preventing disease progression. A study with physiotherapists in PHC demonstrated that postoperative surgery and complex acute cases were considered priorities for referral to secondary care, indicating that the clinical perception of physiotherapists is coincident with the protocol criteria. ${ }^{20}$ The $94.7 \%$ coincidence for defining referral and $72 \%$ for urgency observed in the present study reaffirm the relation reported by Igwesi-Chidobe et. al. ${ }^{17}$ between the ICF and the clinical reasoning in musculoskeletal rehabilitation, which the protocol is able to capture and quantify, helping organize demand.
Urogynecology exhibited the lowest agreement percentage for referral (27.6\%) and urgency classification (37.5\%). One possible explanation is that the protocol was proposed based on the ICF, but the highest scores were for structure and function, which may be less compromised in the care of pregnant women and older adults with urinary complaints, for example. ${ }^{10}$ Despite the fact that physiotherapy is indicated as the first treatment option for urinary continence, there are relatively few public physiotherapy services for incontinent women in Brazil. ${ }^{21}$ Historically, urogynecological disorders, such as urinary incontinence and prolapse, are treated by surgery and medication, and the benefits of physiotherapy for these dysfunctions remain unknown by a large part of the population. ${ }^{21,22}$ Thus, the protocol may not be effective in determining the referral of patients who need urogynecological treatment.

The other physiotherapy specialties analyzed in the research exhibited slight or poor Cohen's Kappa and lower agreement percentages than those found in the musculoskeletal or gerontological areas. One possible explanation may be the fact that their specificity contrasts with the generalist profile of physiotherapists working in $\mathrm{PHC},{ }^{3}$ reflected here in the limited definition of the urgency of the referral. Another possibility is the fact that the protocol is a genuinely generalist instrument and for this reason, does not consider the particular aspects of the specialties. ${ }^{4,10}$

Adults, mainly women, predominated in the sample of referred patients in this study. Women typically represent a majority of patients treated by public health services, including physiotherapy. This is due to their longer life expectancy, greater concern with health, more exposure to the risk factors for disease due to the roles they play and the predominance of health policies aimed primarily at women. Men seek health services less frequently due to embarrassment and anxiety. ${ }^{23}$

A large number of patients examined in PHC were referred for physiotherapy. One of the reasons that may justify the significant demand is the small number of physiotherapists working in BHUs. Braide et al. ${ }^{24}$ found that the number of physiotherapists available is low for the demand of patients that require treatment at BHUs, thereby hindering access to this service and consequently allowing health problems to persist, compromising the longitudinality of care. Almeida et al. ${ }^{25}$ and Goodwin et al. ${ }^{26}$ showed that including physiotherapy in $\mathrm{PHC}$ may lead to greater resolution in 
interdisciplinary actions, in addition to the Family Health Strategy, which strengthens the primary level as a field of operation for these professionals.

With respect to the specialties studied, most of the referrals to the secondary level of Health Care Networks ( $\mathrm{HCN}$ ) were for physiotherapy aimed at treating musculoskeletal disorders. This large demand is due to the lifestyle and behavioral changes of modern society, in addition to repetitive and high-speed work routines, which contribute to overloading the musculoskeletal system, causing pain, injuries and poor posture. ${ }^{17,27}$ On the other hand, the study observed low demand for cardiac rehabilitation, which has numerous benefits for patients with cardiovascular diseases, such as guidelines on physical activities, supervised exercises and management of risk factors such as dyslipidemia, overweight, hypertension, diabetes mellitus and smoking. Nevertheless, Buys et al. ${ }^{28}$ reported low participation levels in cardiac rehabilitation programs and high abandonment. According to Zhang et al., ${ }^{29}$ the low participation in Brazil may be due to a lack of medical indication, few available patients and the popular belief that cardiac rehabilitation is not necessary. Ribeiro et al. ${ }^{30}$ and Buys et al. ${ }^{28}$ also corroborate these results and underscore that a number of personal factors may also lead to low demand, such as transport problems and perceived tiredness.

Study limitations include not monitoring patients who remained in $\mathrm{PHC}$ and considering only those that were referred and included on the spreadsheet, which precluded comparing the clinical perception of physiotherapists and the protocol in terms of non-referral to the secondary level. As strong points, the study is the first to compare the clinical perception of physiotherapists and a protocol for screening at physiotherapy services, underscoring that these protocols may reflect real patient needs and help manage flow.

The practical application of the results of the present study is the importance of including a protocol in the daily routine of $\mathrm{PHC}$ physiotherapists and that it can reflect their conduct. Objective instruments like the one described here help standardize patient-oriented decisions and organize demands, thereby ensuring more equitable access to specialized services. Physiotherapists and healthcare managers should encourage the use of this tool, in order to better organize demand, which will reflect in patient satisfaction.

\section{Conclusion}

As a tool, the protocol was able to help professionals guide patients and optimize flow within the service, given that agreement between its results and the perception of physiotherapists was significant. Thus, it can be used as a decision-making tool to systematize referrals and avoid long waiting lists for secondary services, especially for musculoskeletal and gerontological disorders.

\section{Acknowledgments}

The authors thank the Coordination for the Improvement of Higher Education Personnel (CAPES) and the Universidade Federal de Alfenas.

\section{Authors' contributions}

LBM and FLSC collected data and wrote the manuscript. LBM, TLS e SLAS compiled the data into tables. TLS also organized the services to apply the instrument, and SLAS advised the research, analyzed the data and interpreted the results. All authors designed and organized the study and approved the final version for publication.

\section{References}

1. Arruda C, Lopes SGR, Koerich MHAL, Winck DR, Meirelles BHS, Mello ALSF. Redes de atenção à saúde sob a luz da teoria da complexidade. Esc Anna Nery. 2015;19(1):169-73. DOI

2. Lopes SSS, Figueiredo AMFM, Durães DTS, Sales JWB, Pacheco MDS, Barbosa AAD. A atenção primária como porta de entrada para o sistema de saúde: a visão do usuário. Rev Norte Mineira Enferm. 2015;4(Ed Esp):11-2. Full text link

3. Braghini CC, Ferretti F, Ferraz L. The role of physical therapists in the context of family health support centers. Fisioter Mov. 2017;30(4):703-13. DOI

4. CREFITO 5. Manual de Especialidades da Fisioterapia. 2017 [cited 2019 Jan 5]. Available from: https://tinyurl.com/5trju8zu 
5. Bispo Jr JP. Fisioterapia e saúde coletiva: desafios e novas responsabilidades profissionais. Cienc Saude Coletiva. 2010;15(Suppl 1):1627-36. DOI

6. Ferretti F, Nierotka RP, Braghini CC, Teo CRPA, Ferraz L, Fanticelli ML. Physical therapist insertion in the Family Health Strategy team: the users' view. Fisioter Mov. 2015;28(3):485-93. $\mathrm{DOI}$

7. Aveiro MC, Aciole GG, Driusso P, Oishi J. Perspectivas da participação do fisioterapeuta no Programa Saúde da Família na atenção à saúde do idoso. Cienc Saude Coletiva. 2011;16(Suppl 1):1467-78. DOI

8. Brasil. Protocolos da Atenção Básica: Saúde das Mulheres. Brasília: Ministério da Saúde; 2016. 230 p. Full text link

9. Brasil. Protocolos de encaminhamento da atenção básica para a atenção especializada. v III. Brasília: Ministério da Saúde; 2016. 46 p. Full text link

10. Silva SLA, Aley NRL, Lima AJ, Almeida AP. Proposta de um protocolo de elegibilidade e encaminhamento para um serviço de Fisioterapia em uma Rede Municipal de Atenção à Saúde. Rev Cient CIF Bras. 2017;7(7):12-26. Full text link

11. Landis JR, Koch GG. The measurement of observer agreement for categorical data. Biometrics. 1977;33(1):159-74. $\mathrm{DOI}$

12. Ferrer MLP, Silva AS, Silva JRK, Padula RS. Microrregulação do acesso à rede de atenção em fisioterapia: estratégias para a melhoria do fluxo de atendimento em um serviço de atenção secundária. Fisioter Pesqui. 2015;22(3):223-30. Full text link

13. Azevedo JMR, Barbosa MA. Triagem em serviços de saúde: percepções dos usuários. R Enferm UERJ. 2007;15(1):33-9. Full text link

14. O'Mahony N, Blake C. Musculoskeletal triage: The experiences of advanced practice physiotherapists in Ireland. Physiother Pract Res. 2017;38(1):7-16. DOI

15. Cavanaugh JC, Blanchard-Fields F. Adult development and aging. Boston, MA: Cengage Learning; 2018. 496 p.
16. Jansen-Kosterink $S$, van Velsen L, Frazer S, Dekker-van Weering M, O'Caoimh R, Vollenbroek-Hutten M. Identification of community-dwelling older adults at risk of frailty using the PERSSILAA screening pathway: A methodological guide and results of a large-scale deployment in the Netherlands. BMC Public Health. 2019;19:504. DOI

17. Igwesi-Chidobe CN, Bartlam B, Humphreys K, Hughes $\mathrm{E}$, Protheroe J, Maddison J, et al. Patient direct access to musculoskeletal physiotherapy in primary care: perceptions of patients, general practitioners, physiotherapists and clinical commissioners in England. Physiotherapy. 2019;105(Suppl 1): E31. DOI

18. Kennedy PC, Purtill H, O'Sullivan K. Musculoskeletal pain in Primary Care Physiotherapy: Associations with demographic and general health characteristics. Musculoskelet Sci Pract. 2018:35:61-6. DOI

19. Matifat E, Méquignon M, Cunningham C, Blake C, Fennelly O, Desmeules F. Benefits of musculoskeletal physical therapy in emergency departments: a systematic review. Phys Ther. 2019;99(9):1150-66. DOI

20. Lima AJ, Lemes NR, Britto GEG, Goyatá SLT, Silva SLA. Resolutividade da fisioterapia na atenção básica à saúde (AB): a percepção de fisioterapeutas. Cad Edu Saude e Fis. 2017;4(8):14-22. DOI

21. Pereira AGP, Mejia DPM. O papel da fisioterapia no prolapso uterino [cited 2019 Dez 4]. Available from: https://tinyurl. com/2pubw27m

22. Wiegersma M, Panman CMCR, Hesselink LC, Malmberg AGA, Berger MY, Kollen BJ, et al. Predictors of success for pelvic floor muscle training in pelvic organ prolapse. Phys Ther. 2019;99(1):109-17. DO।

23. Yousaf $O$, Grunfeld EA, Hunter MS. Systematic review of the factors associated with delays in medical and psychological helpseeking among men. Health Psychol Rev. 2015;9(2):264-76. DOI

24. Braide ASG, Oliveira MCX, Gadelha NNT, Pinto ERS, Nascimento FNS, Caldas JMP. Narrativa do usuário sobre o acesso a unidade básica de saúde e encaminhamento ao tratamento fisioterapêutico. CIAIO. 2019;2:1090-5. Full text link 
25. Almeida SM, Martins AM, Escalda PMF. Integralidade e formação para o Sistema Único de Saúde na perspectiva de graduandos em Fisioterapia. Fisioter Pesq. 2014;21(3): 271-8. Full text link

26. Goodwin R, Moffatt F, Hendrick P, Logan P. Sociocultural challenges faced in implementing self-referral physiotherapy in primary care - a qualitative evaluation of staff opinions. Physiotherapy. 2017;103(Suppl 1):E6. DOI

27. French HP, Galvin R. Musculoskeletal services in primary care in the Republic of Ireland: an insight into the perspective of physiotherapists. Physiotherapy. 2017;103(2):214-21. DOI
28. Buys R, Claes J, Walsh D, Cornelis N, Moran K, Budts W, et al. Cardiac patients show high interest in technology enabled cardiovascular rehabilitation. BMC Med Inform Decis Mak. 2016;16:95. Full text link

29. Zhang L, Sobolev M, Piña IL, Prince DZ, Taub CC. Predictors of cardiac rehabilitation initiation and adherence in a multiracial urban population. J Cardiopulm Rehabil Prev. 2017;37(1):30-8. DOI

30. Ribeiro ALP, Duncan BB, Brant LC, Lotufo PA, Mill JG, Barreto SM. Cardiovascular health in Brazil: trends and perspectives. Circulation. 2016;133(4): 422-33. DOI 